Macedonian Pharmaceutical Bulletin, 66 (Suppl 1) 163 - 164 (2020)

Online ISSN 1857 - 8969

UDC: $615.015 .11: 340.13(73)$

DOI: 10.33320/maced.pharm.bull.2020.66.03.081

Short communication

\title{
Regulatory approaches for medicines containing established active substances in USA
}

\author{
Bojana Danilova $^{1}$, Jasmina Tonic Ribarska ${ }^{2}$, Suzana Trajkovic Jolevska ${ }^{2}$, \\ Katerina Brezovska ${ }^{2}$, Jelena Lazova ${ }^{1}$
}

\author{
${ }^{1}$ Alkaloid AD Skopje, Blvd. Aleksandar Makedonski 12, 1000 Skopje, Republic of North Macedonia \\ ${ }^{2}$ Faculty of Pharmacy, Ss Cyril and Methodius University, 1000 Skopje, Republic of North Macedonia
}

\section{Introduction}

The term "Established Active Substance" refers to an active pharmaceutical ingredient (API) that is identical to an API already in a drug product, which is approved for marketing in the United States of America (USA) under section 505 of the Federal Food, Drug, and Cosmetic Act (FD\&C Act).

In this study, the regulatory requirements for the medicines containing established active substances and possible regulatory approaches for line extensions and generics have been studied in line with the USA governing laws and regulatory environment. The aim is to critically overview the use, the requirements and the outcome of different regulatory procedures suitable for the abridged applications.

\section{Regulatory background}

The Federal Food, Drug, and Cosmetic Act (FD\&C Act) and the FDA Rules and Regulations published under Title 21 of Code of Federal Regulations as well as the effective Guidelines for industry, information available in the official FDA website and published journal articles have been reviewed in order to collect data and develop a regulatory strategy for medicines containing established active substances.

\footnotetext{
*bdanilova@alkaloid.com.mk
}

Once the New Molecular Entity NDA (New Drug Application) is approved by FDA under the section 505(b)(1) of the FD\&C Act, the medicines containing established substances options for submissions are as follows:

\section{SNDA - Supplemental New Drug Application}

This application can be submitted only by the NDA owner, as it relates to changing the already approved NDA, which may result with line extensions. Subject to SNDA can be changes for which prior approval is required, including changes in the drug substance, drug product or labelling (i.e. change in composition, indications, dosing regimen, additional strength, form etc.) and changes for which prior approval is not required (i.e. tightening the manufacturing controls, safety changes in labelling, etc.), also known as "Changes Being Effected".

\section{ANDA - Abbreviated New Drug Application}

This type of application is filed for generic drug 'copy' of an existing licensed medication. The basis for ANDA were established by the "Drug Price Competition and Patent Term Restoration Act of 1984", also known as the "Hatch-Waxman Act". The exclusion of the pre-clinical and clinical trials, the introduction of bioequivalence study only, the reduction of time and cost for placing generic drugs 
on the market, Roche-Bolar provision, are just a few of the many significant results due to this Act. According to the 21CFR314.92, the drug product eligible for ANDA should be same as the Reference Listed Drug (RLD) chosen by FDA in terms of active ingredient(s), strength, dosage form, route of administration, as well as quality and performance characteristics, bioavailability and intended use. For drugs that differ from the RLD, Suitability Petition under the section 505(j)(2)(C) from the FD\&C Act should be submitted in order FDA to determine if the product is eligible for ANDA. ANDA data requirements include bioequivalence study (must demonstrate $\mathrm{BE}$ to RLD), CMC data (complete quality dossier and comparable dissolution data vs RLD) and Labelling (same as RLD, minus exclusivity). ANDA must include Patent certifications for each patent listed in the "Orange Book" for the RLD. The first generic drug approved under patent certification for paragraph IV (claiming that the patent of the RLD will not be infringed by the ANDA), gains 180 days of market exclusivity. With implementation of Generic Drug User Fee Act (GDUFA), the standard review time has been shortened to 10 months. The priority review is reserved for first ANDAs, market shortages etc. and the review time goal is set to 8 months.

\section{5(b)(2) NDA}

"Hatch-Waxman Act" has also established basis for approving drugs by relying on literature studies and previous public FDA findings, avoiding unnecessary duplication of studies already performed. This application contains "full reports of investigations of safety and effectiveness, where at least some of the information required for approval comes from studies not conducted by or for the applicant and for which the applicant has not obtained a right of reference or use". A 'hybrid' procedure that requires a bridge between the new version of the product and the RLD(s). This could include data and results of bioanalytical testing, preclinical studies, or even clinical trial results. These drugs are not strictly generics, but are often not entirely novel new molecular entities either. 505(b)(2) candidates are drugs with a new aspect related to indication, dosage form, strength, formulation, dosing regimen, route of administration, dispensing regimen (Rx-OTC), new combination, prodrugs of an existing drug, and in some cases, drugs with new API (different salt). This pathway is not appropriate for duplicates of RLD or if the only difference from the RLD is decreased rate or extent of absorption. Appealing aspect is that the 505(b)(2) approved drug is eligible for 3, 5 or 7 years of market exclusivity. According to Prescription Drug User Fee Act (PDUFA), the standard review time is 10 months, and a 6 months goal is established for priority review NDAs.

\section{OTC applications}

If the OTC drug complies with the corresponding FDA OTC monograph, no FDA approval is needed to market the drug. If the OTC drug does not comply with a OTC monograph, than the following applications should be considered: OTC NDA, OTC 505(b)(2) NDA, OTC ANDA or SNDA of an existing Rx NDA. The Time and Extent Application (TEA) under the section 21CFR 330.14 is another mechanism to incorporate a "new product or a product condition" in a monograph. This twostep process includes review of condition eligibility for inclusion in the OTC drug monograph system, followed by safety and effectiveness data submission for the determined conditions as eligible.

\section{Summary}

When determining the appropriate regulatory strategy for approval of a product that contains established active substance(s), it is important firstly to identify the proposed product characteristics with respect to the listed drug(s). The exact RLD 'copies' are suitable for ANDAs. The diverse products from RLD, may be suitable for 505(b)(2) NDA or 'Petitioned ANDA'. If OTC, consider marketing per monograph or submitting NDA/ANDA.

\section{References}

U.S. Congress. United States Code: Federal Food, Drug, and Cosmetic Act, Chapter V, Subchapter A, sec. 505. [21 U.S.C. 355], Revised as of August 2, 2019 or 21 CFR part 300-370 Revised as of January 31, 2020.

U.S. Food and Drug Administration website. https://www.fda.gov/drugs/resources-you-drugs/ information-industry-drugs\#CDER\%20Small \%20Business (Last assessed: February 2020).

Maced. Pharm. Bull. 66 (Suppl 1) 163 - 164 (2020) 